\title{
Toxoplasmosis among Saudi Female Students in Al-Ahssa, Kingdom of Saudi Arabia: Awareness and Risk Factors
}

\author{
Noura Alrashada, Zainab Alqarash, Fatimah Alshehri, Layla Al-Khamees, Afnan Alshqaqeeq \\ Faculty of Medicine, King Faisal University, Al-Hassa, Saudi Arabia \\ Email: fatmaalshehri26@gmail.com
}

Received 11 July 2016; accepted 23 August 2016; published 26 August 2016

Copyright (C) 2016 by authors and Scientific Research Publishing Inc.

This work is licensed under the Creative Commons Attribution International License (CC BY). http://creativecommons.org/licenses/by/4.0/

(c) (i) Open Access

\begin{abstract}
Background: Toxoplasmosis is a worldwide disease that severely affects the fetuses and immunocompromised patients and results in many critical and life threatening conditions. The present study aimed to evaluate the awareness of toxoplasmosis and its preventive behaviors among female students in King Faisal University in Al-Ahssa. Subjects and methods: A cross sectional study was conducted in April 2014 among female students in KFU. The data were collected by a questionnaire from 88 participants. Results: Results showed that $65.4 \%$ were not aware of toxoplasmosis, and only $\mathbf{2 8 . 2 \%}$ were aware of its complications or risk factors. This study showed that some people are at risk to get toxoplasmosis as they do not wash their hands with water and soap before eating (48.8\%), do not wash the fruits and vegetables with water and soap (78.2\%), drink tank water (51.3\%) and cat owners don't follow the proper measures for their cats. However, some people practice some of the preventive behaviors as they do not raise the cats $(93.6 \%)$ and do not consume unpasteurized or unboiled milk (100\%) or undercooked meat $(\mathbf{9 2 . 3 \% )}$ ). Conclusion: The current study proved the low awareness of toxoplasmosis which emphasized the need to educate the people in Al-Ahssa about the preventive methods, especially the pregnant women to prevent the severe complications of congenital infections.
\end{abstract}

\section{Keywords}

Toxoplasmosis, Congenital Toxoplasmosis, Awareness, Risk Factors, Al-Ahssa

\section{Introduction}

Toxoplasmosis is a disease caused by the protozoal parasite Toxoplasma gondii [1]. Studies show that $T$. gondii

How to cite this paper: Alrashada, N., Alqarash, Z., Alshehri, F., Al-Khamees, L. and Alshqaqeeq, A. (2016) Toxoplasmosis among Saudi Female Students in Al-Ahssa, Kingdom of Saudi Arabia: Awareness and Risk Factors. Open Journal of Preventive Medicine, 6, 187-195. http://dx.doi.org/10.4236/ojpm.2016.68018 
infects up to a third of the world's population [2]. Humans are usually infected with T. gondii by ingestion of oocysts in food or water that has been contaminated with cat feces or by ingestion of tissue cysts in undercooked meat. Congenital transmission, organ transplantation and blood transfusion are other routes of the infection [3] $[4]$.

Congenital toxoplasmosis generally occurs when a woman is newly infected with $T$. gondii during pregnancy [5], although rare exceptions have been reported in which women were infected just before pregnancy [6]. In addition, in immunosuppressed women, reactivation of a latent infection can lead to congenital toxoplasmosis [7]. Exposure to infection acquired in the first trimester causes more severe congenital illness [8] and it may lead to intra-uterine growth retardation, premature birth [9] or spontaneous abortion [10]. Also, some severely affected infants die in utero or within a few days of birth. Signs of congenital toxoplasmosis at birth can include a maculopapularrash, generalized lymphadenopathy, hepatomegaly, splenomegaly, jaundice, ventricular dilatation, intracranial calcification, and thrombocytopenia. Furthermore, it can result in meningoencephalitis, seizures, chorioretinitis, deafness, hydrocephalus and microcephaly. Some fetuses exposed in the third trimester are more likely to be asymptomatic at birth, although visual impairment, learning disabilities, or mental retardation will become apparent in a large proportion of children several months to years later [11] [12].

T. gondii primary infection in immunocompetent children and adults (including pregnant women) is asymptomatic in most patients. When symptoms develop, they are nonspecific and include malaise, fever, headache, lymphocytosis, sore throat, and myalgia. Lymphadenopathy, frequently cervical, is the most common sign. Occasionally, patients may have a mononucleosis-like illness associated with a macular rash and hepatosplenomegaly [11] [13]. However, toxoplasmosis among immunocompromised patients manifests primarily as a life threatening condition, toxoplasmic encephalitis. Pneumonia can also be seen but are not as common as toxoplasmic encephalitis [14] [15].

Isolated ocular toxoplasmosis commonly results from reactivation of untreated congenital infection but also occurs in a small percentage of people with acquired infection [11]. It can cause choroidal neovascularization, cataract, glaucoma, optic nerve atrophy and retinal detachment, which are more frequently in children [16].

Providing an adequate knowledge about toxoplasmosis and its risk factors is considered as powerful preventive method. Many studies have been done to assess the level of awareness about toxoplasmosis around the world. The awareness level among most of childbearing aged female students in King Abdulaziz University in Jeddah city, Saudi Arabia was sufficient [17]. Another study that was done in Netherlands to evaluate the awareness among the pregnant women had revealed that about $76 \%$ of the women had read, seen or heard information about this infection [18]. However, among the pregnant women from Malaysia, Philippines, and Thailand, many women had no information concerning toxoplasmosis and how to avoid it during the pregnancy [19]. Likewise, the awareness level of toxoplasmosis was 4.4\% among the pregnant women in Sri Lanka [20]. Furthermore, a study that was carried out in primary health care centers in Al-Ahssa, Saudi Arabia, had revealed that a substantial part of the pregnant women did not have a sufficient knowledge about the prevention [21].

High prevalence of infection has been reported among pregnant women and women of childbearing age from different parts of the world including the Middle East [2]. In Saudi Arabia, the prevalence of infection showed wide variations as revealed from previous studies at different parts of the Kingdom. The highest positivity rate was reported in Jeddah 61.4\% [22], Al-Ahssa of 51.4\% [23] and 35.6\% in Makkah [24]. Thus, the pregnant women in Al-Ahssa are substantially vulnerable to toxoplasmosis [21]. The aim of this study is to assess the risk behavior, preventive practices and the awareness of toxoplasmosis among female students in King Faisal University in Al-Ahssa, especially regarding the risk behaviors.

\section{Subjects and Methods}

\subsection{Study Design}

A cross sectional study was prepared to assess the awareness of toxoplasmosis and risk behavior among participants.

\subsection{Study Area and Population}

This study was conducted in April 2014 among female students in KFU from scientific and art colleges excluding students of Faculty of Medicine. One hundred students receive the questionnaire, and eighty-eight students 
respond. The students in this study were randomly selected. The sample size was calculated by Creative Research Systems Survey software with confidence level 95\%.

\subsection{Questionnaire Sheet}

A well-structured questionnaire (Appendix 1) was designed in Arabic including biographical data: age, name of the college, social status and pregnancy. Also, it includes twelve questions about the awareness of toxoplasmosis and its risk factors including raising cats, source of water and milk, rate of eating improper cooked meat, washing of hands before eating and washing of fruits and vegetables before eating them. This questionnaire was tested first in a pilot study that was not included in the current study. Then, it was distributed among participants preceded by oral briefing for the aim of the study.

\subsection{Statistical Analysis}

The statistics was performed by using software program SPSS version 21. Data were presented as frequencies and percentages. Also, the chi-square test was used for the comparison and to assess the possible associations of the type of college and the awareness of toxoplasmosis to the significant point (Significant level P $<0.05$ ).

\section{Results}

\subsection{General Biographical Data}

Eighty- eight female students were involved in this study. Ten of them were excluded for some deficiencies. The general biographical data are shown in Figure $1 \&$ Figure 2. Participants with age 18 - 20 years old were $43.6 \%, 53.8 \%$ with age $21-24$ years and only $2.6 \%$ were more than 24 years old. The majority of the participants $(73.1 \%)$ were not married, and about $17.9 \%$ of the married participants got pregnant.

\subsection{Awareness of Toxoplasmosis}

Table 1 presents the percentages and frequencies of the questionnaire results. $34.6 \%$ of the participants were aware of toxoplasmosis, and only $28.2 \%$ were aware of its severity or risk factors. $19.2 \%$ obtained their information from their relatives and studying, $6.4 \%$ of the participants obtained their information about toxoplasmosis from the media and $2.6 \%$ obtained their information from awareness campaigns. The results in Table 2 showed that the awareness level about toxoplasmosis in general differ significantly between scientific and lite-

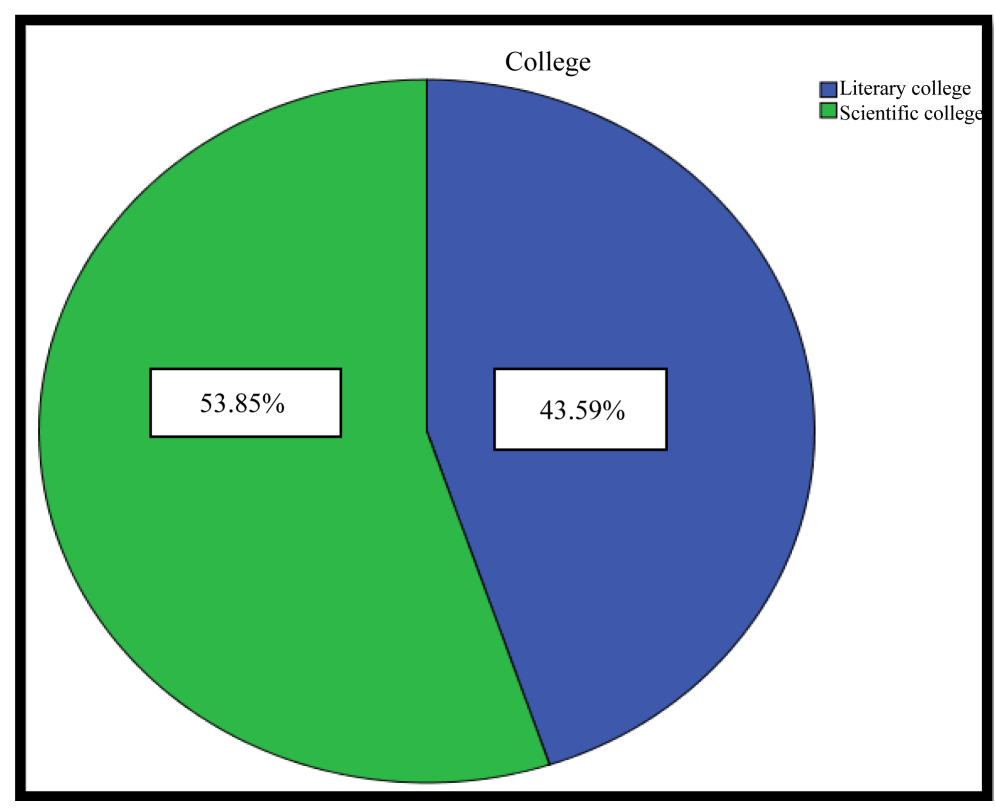

Figure 1. College of the female participants from King Faisal University. 


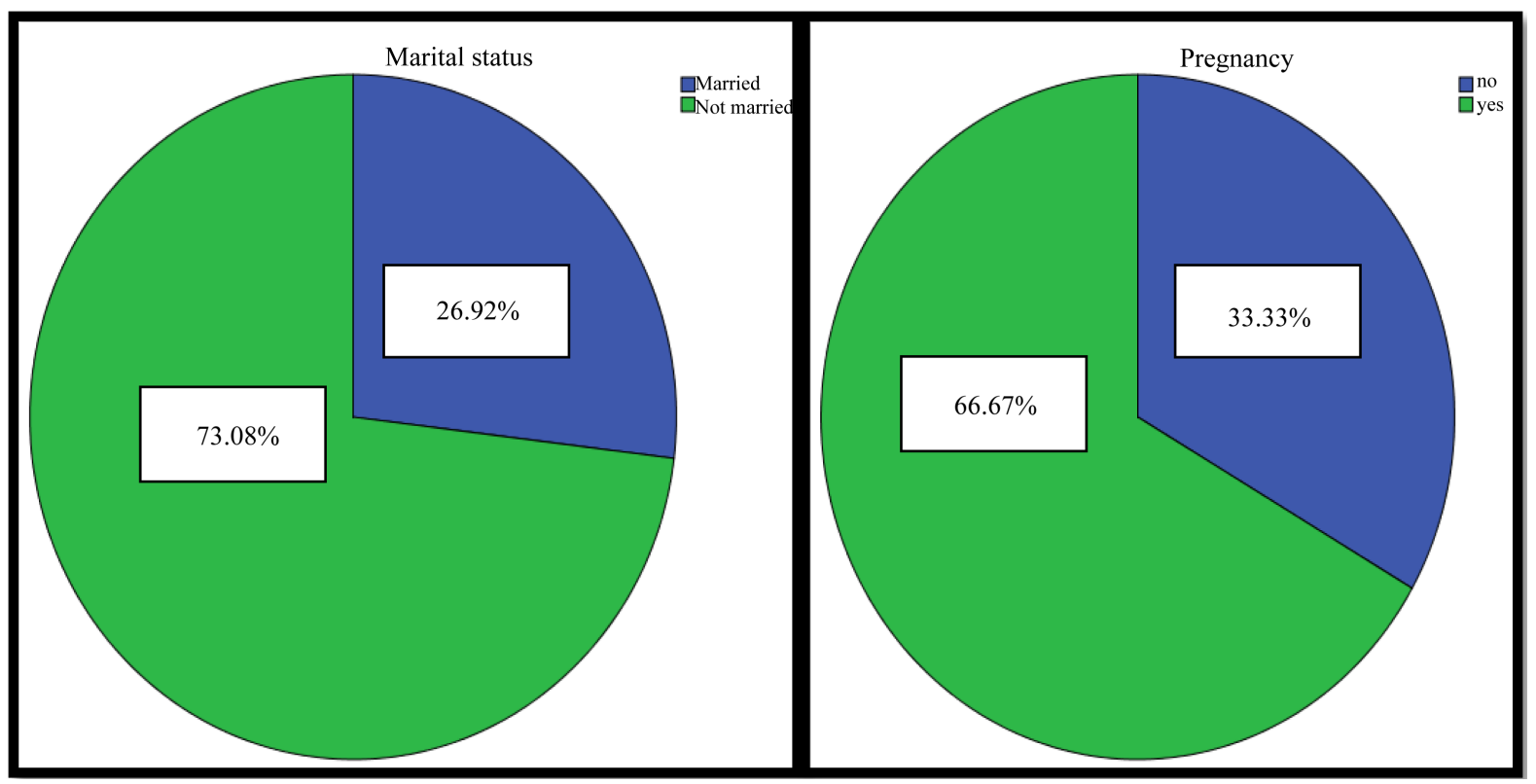

Figure 2. Distribution of participants according to marital status and previous pregnancy.

Table 1. Awareness of toxoplasmosis.

\begin{tabular}{|c|c|c|c|}
\hline \multicolumn{2}{|c|}{ Variables } & Frequency & Percentage \% \\
\hline \multirow{2}{*}{ Awareness of toxoplasmosis } & Yes & 27 & 34.6 \\
\hline & No & 51 & 65.4 \\
\hline \multirow{2}{*}{$\begin{array}{l}\text { Awareness of complications of } \\
\text { toxoplasmosis or its risk factors }\end{array}$} & Yes & 22 & 28.2 \\
\hline & No & 56 & 71.8 \\
\hline \multirow{4}{*}{ Sources of information } & Media & 5 & 6.4 \\
\hline & Awareness campaigns & 2 & 2.6 \\
\hline & Others* & 15 & 19.2 \\
\hline & NA & 56 & 71.8 \\
\hline
\end{tabular}

$\mathrm{NA}=$ Not Applicable. ${ }^{*}$ Involves the relatives and the studying.

Table 2. Awareness of toxoplasmosis regarding the college.

\begin{tabular}{|c|c|c|c|c|}
\hline \multirow{2}{*}{ Variable } & & \multicolumn{2}{|c|}{ College } & \multirow{2}{*}{ P-Value } \\
\hline & & Arts colleges & Scientific colleges & \\
\hline \multirow[b]{2}{*}{ Awareness of toxoplasmosis } & No & $28(54.9 \%)$ & $23(45.1 \%)$ & \multirow[b]{2}{*}{$0.014^{*}$} \\
\hline & Yes & $7(25.9 \%)$ & $20(74.1 \%)$ & \\
\hline \multirow{2}{*}{$\begin{array}{l}\text { Awareness of complications of } \\
\text { toxoplasmosis and risk factors }\end{array}$} & No & $2(40 \%)$ & $3(60 \%)$ & \multirow{2}{*}{$0.429 * *$} \\
\hline & Yes & $5(22.7 \%)$ & $17(77.3 \%)$ & \\
\hline
\end{tabular}

*Significant. **Not significant.

rary colleges. However, no significant difference was observed between both of them regarding more detailed information about toxoplasmosis (Table 2). 


\subsection{Potential Risk Factors of Toxoplasmosis}

Table 3 displays that most of the participants (93.6\%) did not raise the cats and the majority of cat owners about $5.1 \%$ clean their cats' boxes every two days. However, only three participants $(3.8 \%)$ seek the medical examination for their cats. Furthermore, only $50 \%$ of the participants wash their hands before eating with water and soap.

Table 3. Risk factors of toxoplasmosis.

\begin{tabular}{|c|c|c|c|}
\hline \multicolumn{2}{|c|}{ Variables } & \multirow{2}{*}{$\begin{array}{c}\text { Frequency } \\
5\end{array}$} & \multirow{2}{*}{$\begin{array}{c}\text { Percentages \% } \\
6.4\end{array}$} \\
\hline & Yes & & \\
\hline & No & 73 & 93.6 \\
\hline \multirow{3}{*}{ Cleaning the cats' boxes } & Every two days & 4 & 5.1 \\
\hline & More & 1 & 1.3 \\
\hline & NA & 73 & 93.6 \\
\hline \multirow{3}{*}{ Medical examination of the cats } & No & 2 & 2.6 \\
\hline & Yes & 3 & 3.8 \\
\hline & NA & 73 & 93.6 \\
\hline \multirow{4}{*}{ Washing hands before eating } & No & 2 & 2.6 \\
\hline & Yes, with water only & 36 & 46.2 \\
\hline & Yes, with water and soup & 39 & 50 \\
\hline & Others* & 1 & 1.3 \\
\hline \multirow{4}{*}{$\begin{array}{l}\text { Washing the fruits and the } \\
\text { vegetables before eating them }\end{array}$} & No & 1 & 1.3 \\
\hline & Yes, with water only & 60 & 76.9 \\
\hline & Yes, with water and soap & 16 & 20.5 \\
\hline & Others** & 1 & 1.3 \\
\hline \multirow{3}{*}{ Source of drinking water } & Bottles & 38 & 48.7 \\
\hline & From refill companies (Baider Water) & 28 & 35.9 \\
\hline & Both & 12 & 15.4 \\
\hline \multirow{6}{*}{ Cleaning the tank } & Always & 3 & 3.8 \\
\hline & Usually & 4 & 5.1 \\
\hline & Some times & 1 & 1.3 \\
\hline & Rarely & 2 & 2.6 \\
\hline & I don't know & 31 & 39.7 \\
\hline & NA & 37 & 47.4 \\
\hline \multirow{3}{*}{ Eating the half-cooked meat } & Some times & 3 & 3.8 \\
\hline & Rarely & 3 & 3.8 \\
\hline & Never & 72 & 92.3 \\
\hline \multirow{3}{*}{ Kind of drinking milk } & Canned milk & 69 & 88.5 \\
\hline & Cows' and camels' milk after boiling & 1 & 1.3 \\
\hline & I do not boil milk & 8 & 10.3 \\
\hline
\end{tabular}

*Includes combination of water, soap and sterilizer. **Includes combinations of water, soap and vinegar. 
Also, $1.3 \%$ of the participants do not wash the fruits and vegetables before eating them and the majority of participants $(76.9 \%)$ wash them with only water. There were three participants $(3.8 \%)$ who sometimes eat the halfcooked meat and three (3.8\%) who rarely eat it. Additionally, 35.9\% drink water from refill companies (Baider water) and twelve participants (15.4\%) drink both bottled water and refill companies (Baider water).

\section{Discussions}

Toxoplasmosis is considered as the most prevalent parasitic zoonotic disease worldwide [25]. Many factors can affect seroprevalence in humans. Climatic factors affect the survival of oocysts in the environment and infection rates in meat-producing animals also play a major role. Higher prevalence is classically observed in tropical countries with a humid and warm climate, and conversely, lower prevalence is found in arid countries or for colder countries. Other factors include dietary habits (method of cooking meat, hand washing, kinds of meat or vegetables consumed, and vegetable cleaning, etc.); economic, social, or cultural habits; quality of water; and sanitation coverage [26]-[28].

The present study demonstrates low awareness about toxoplasmosis, its danger and risk factors. Of 78 female students in King Faisal University, who responded to the survey, 34.6\% know about the toxoplasmosis and only $28.2 \%$ are aware of its complications or risk factors. These results are in agreement with another study among pregnant women in Makkah, Saudi Arabia which revealed that only around $10 \%$ of the participants were aware of the toxoplasmosis [24]. In Brazil, studies presented that only $35 \%$ of included pregnant women knew about this disease [29]. $77.3 \%$ of the aware participants have studied in scientific colleges which indicate that education represents one of the major sources of the information about toxoplasmosis. Amin et al. (2013) showed that the major source of information about the disease among Saudi pregnant women was the internet [21].

Regardless that most of the participants do not know about the toxoplasmosis, their habits help them to avoid many of its risk behaviors as they do not raise the cats (93.6\%), do not consume undercooked meat $(92.3 \%)$ and unpasteurized or not boiled milk $(100 \%)$. Also, as they wash their hands with water and soap before eating (51.3\%). These findings are close to those of Amin et al. (2013) [21] which showed that $98.2 \%$ did not contact with cat and cat's litter, $82.6 \%$ did not eat undercooked and raw meat, but about $50 \%$ of them did not wash their hands after dealing with raw meats and vegetables.

However, this study reveals that more than $50 \%$ of the participants drink unfiltered water. Drinking tank water have been documented to have an influence on $T$. gondi transmission in different parts of the world as reported by Remington et al. (2001) [10] and Montoya \& Liesenfeld (2004) [3]. Oocysts can remain viable for long periods of time in water and can resist freezing and moderately high water temperatures [30]. Furthermore, $78.2 \%$ are susceptible to toxoplasmosis as they do not wash the fruits and vegetables with water and soap before eating them since the raw fruits and vegetables may be contaminated with the oocysts [31].

Also, in this study, about $6.4 \%$ are at risk of getting toxoplasmosis because they have cats in their houses and they do not clean their boxes daily. Also, some of them do not seek the medical examination for their cats. The cats are the main sources of environmental contamination, because, when infected, they release large quantities of oocysts which are estimated to be more than 100 million oocysts by a single cat, allowing for the continuity of the parasite biological cycle [25] [32]. These oocysts require at least 24 hours to sporulate and become infectious [33] [34].

\section{Conclusion}

The current study proved the low level of knowledge about toxoplasmosis among female students in King Faisal University. However, most of the preventive behaviors that are applied could be explained by the economic, religious and cultural habits in Al-Ahssa. Likewise, this study reflects the necessity to educate people about the hygienic measures which are essential to avoid the infection. These measures include the personal hygiene, applying safe water supply, eating healthy and clean food, checking the cats regularly and changing their litter box daily. Furthermore, the physicians should be at the first line to educate the women who are pregnant or plan to be pregnant in order to reduce the risk of congenital toxoplasmosis.

\section{Limitation of the Study}

Not all students have returned the questionnaire back and some questions left unanswered. Those were excluded from the results. 


\section{Acknowledgements}

The authors gratefully acknowledge the Deanship of Scientific Research, King Faisal University of Saudi Arabia, for its financial support concerning this research project and Dr. Dalia Ashour for mentoring this research.

\section{References}

[1] Dubey, J. (2008) The History of Toxoplasma gondii-The First 100 Years. The Journal of Eukaryotic Microbiology, 556, 467-475. http://dx.doi.org/10.1111/j.1550-7408.2008.00345.x

[2] Pappas, G., Roussos, N. and Falagas, M.E. (2009) Toxoplasmosis Snapshots: Global Status of Toxoplasma gondii Seroprevalence and Implications for Pregnancy and Congenital Toxoplasmosis. International Journal for Parasitology, 39, 1385-1394. http://dx.doi.org/10.1016/j.ijpara.2009.04.003

[3] Montoya, J.G. and Liesenfeld, O. (2004) Toxoplasmosis. The Lancet, 363, 1965-1976. http://dx.doi.org/10.1016/S0140-6736(04)16412-X

[4] Dubey, J.P. and Jones, J.L. (2008) Toxoplasma gondii Infection in Humans and Animals in the United States. International Journal for Parasitology, 38, 1257-1278. http://dx.doi.org/10.1016/j.ijpara.2008.03.007

[5] Remington, J.S., McLeod, R., Thulliez, P. and Desmonts, G. (2006) Toxoplasmosis. In: Remington, J.S., Klein, J.O., Wilson, C.B. and Baker, C.J., Eds., Infectious Diseases of the Fetus and Newborn Infant, Elsevier Saunders, Philadelphia, 947-1091. http://dx.doi.org/10.1016/B0-72-160537-0/50033-5

[6] Elbez-Rubinstein, A., Ajzenberg, D., Dardé, M., Cohen, R., Dumètre, A., Year, H., Gondon, E., Janaud, J. and Thulliez, P. (2009) Congenital Toxoplasmosis and Reinfection during Pregnancy: Case Report, Strain Characterization, Experimental Model of Reinfection, and Review. The Journal of Infectious Diseases, 199, 280-285. http://dx.doi.org/10.1086/595793

[7] Lindsay, D.S. and Dubey, J.P. (2011) Toxoplasma gondii: The Changing Paradigm of Congenital Toxoplasmosis. Parasitology, 138, 1829-1831. http://dx.doi.org/10.1017/S0031182011001478

[8] Feldman, D.M., Timms, D. and Borgida, A.F. (2010) Toxoplasmosis, Parvovirus, and Cytomegalovirus in Pregnancy. Clinics in Laboratory Medicine, 30, 709-720. http://dx.doi.org/10.1016/j.cll.2010.04.009

[9] Freeman, K., Oakley, L., Pollak, A., Buffolano, W., Petersen, E., Semprini, A.E., et al. (2005) Association between Congenital Toxoplasmosis and Preterm Birth, Low Birthweight and Small for Gestational Age Birth. BJOG, 112, 3137. http://dx.doi.org/10.1111/j.1471-0528.2004.00299.x

[10] Remington, J.S., McLeod, R., Thulliez, P. and Desmonts, G. (2001) Toxoplasmosis. In: Remington, J.S. and Klein, J., Eds., Infectious Diseases of the Fetus and Newborn Infant, 5th Edition, WB Saunders, Philadelphia, 205-346.

[11] Jung, C. (2009) Summaries of Infectious Diseases. In: Red Book. American Academy of Pediatrics, 667-672.

[12] Gay-Andrieu, F., Marty, P., Pialat, J., Sournies, G., Drier de Laforte, T. and Peyron, F. (2003) Fetal Toxoplasmosis and Negative Amniocentesis, Necessity of an Ultrasound Follow-Up. Prenatal Diagnosis, 23, 558-560. http://dx.doi.org/10.1002/pd.632

[13] Antsaklis, A., Daskalakis, G., Papantoniou, N., Mentis, A. and Michalas, S. (2002) Prenatal Diagnosis of Congenital Toxoplasmosis. Prenatal Diagnosis, 22, 1107-1111. http://dx.doi.org/10.1002/pd.476

[14] Shimelis, T., Tebeje, M., Tadesse, E., Tegbaru, B. and Terefe, A. (2009) Sero-Prevalence of Latent Toxoplasma gondii Infection among HIV-Infected and HIV-Uninfected People in Addis Ababa, Ethiopia: A Comparative Cross-Sectional Study. BMC Research Notes, 2, 213. http://dx.doi.org/10.1186/1756-0500-2-213

[15] Schwatzman, J.D. (2001) Toxoplasmosis. In: Gillespie, S. and Pearson, R.D., Eds., Principals and Practice of Clinical Parasitology, John Wiley \& Sons Ltd., New York, 113-138. http://dx.doi.org/10.1002/0470842504.ch5

[16] Bosch-Driessen, L.H., Karimi, S., Stilma, J.S. and Rothova, A. (2000) Retinal Detachment in Ocular Toxoplasmosis. Ophthalmology, 107, 36-40. http://dx.doi.org/10.1016/S0161-6420(99)00013-5

[17] Alshehri, E.M., Atorje, E.O., Basaeed, L.F., et al. (2015) Seropositivity and Awareness of Toxoplasmosis among University Students. International Journal of Clinical \& Laboratory Research, 6, 68-71.

[18] Pereboom, M.T.R., Manniën, J., Spelten, E.R., et al. (2013) Pregnant Women's Awareness of Infectious Diseases.

[19] Andiappan, H., Nissapatorn, V., Sawangjaroen, N., Khaing, S., et al. (2014) Knowledge and Practice on Toxoplasma Infection in Pregnant Women from Malaysia, Philippines, and Thailand. Frontiers in Microbiology, 5, 291. http://dx.doi.org/10.3389/fmicb.2014.00291

[20] Chandrasenaa, N., Herathb, R., Rupasinghea, N., et al. (2016) Toxoplasmosis Awareness, Seroprevalence and Risk Behavior among Pregnant Women in the Gampaha District, Sri Lanka. Pathogens and Global Health, 110, 62-67. http://dx.doi.org/10.1080/20477724.2016.1173325

[21] Amin, T.T., Al Ali, M.N., Alrashid, A.A., Al-Agnam, A.A. and Al Sultan, A.A. (2013) Toxoplasmosis Preventive Be- 
havior and Related Knowledge among Saudi Pregnant Women: An Exploratory Study. Global Journal of Health Science, 5, 131-143. http://dx.doi.org/10.5539/gjhs.v5n5p131

[22] Tonkal, A.M. (2008) The PCR versus ELISA in Diagnosis of Human Toxoplasmosis in Jeddah, Saudi Arabia. Journal of the Egyptian Society of Parasitology, 38, 707-714.

[23] Al-Mohammad, H.I., Amin, T.T., Balaha, M.H. and Al-Moghannum, M.S. (2010) Toxoplasmosis among the Pregnant women Attending a Saudi Maternity Hospital, Sero-Prevalence and Possible Risk Factors. Annals of Tropical Medicine and Parasitology, 104, 493-504. http://dx.doi.org/10.1179/136485910X12786389891443

[24] Al-Harthi, S.A., Jamjoom, M.B. and Ghazi, H.O. (2006) Seroprevalence of Toxoplasma gondii among Pregnant Women in Makkah, Saudi Arabia. Umm Al-Qura University, Journal of Science and Medicine, 18, 217-227.

[25] Tenter, A.M., Heckeroth, A.R. and Weiss, L.M. (2000) Toxoplasma gondii: From Animals to Humans. International Journal for Parasitology, 30, 1217-1258. http://dx.doi.org/10.1016/S0020-7519(00)00124-7

[26] Bahia-Oliveira, L.M., Jones, J.L., Azevedo-Silva, J., Alves, C.C., Oréfice, F. and Addiss, D.G. (2003) Highly Endemic, Waterborne Toxoplasmosis in North Rio de Janeiro State, Brazil. Emerging Infectious Diseases, 9, 55-62. http://dx.doi.org/10.3201/eid0901.020160

[27] Ertug, S., Okyay, P., Turkmen, M. and Yuksel, H. (2005) Seroprevalence and Risk Factors for Toxoplasma Infection among Pregnant Women in Aydin Province, Turkey. BMC Public Health, 5, 66. http://dx.doi.org/10.1186/1471-2458-5-66

[28] Jones, J.L. and Dubey, J.P. (2010) Waterborne Toxoplasmosis-Recent Developments. Experimental Parasitology, 124, 10-25. http://dx.doi.org/10.1016/j.exppara.2009.03.013

[29] Varella, I.S., Canti, I.C., Santos, B.R., Coppini, A.Z., Argondizzo, L.C., Tonin, C. and Wagner, M.B. (2009) Prevalence of Acute Toxoplasmosis Infection among 41,112 Pregnant Women and the Mother-to-Child Transmission Rate in a Public Hospital in South Brazil. Memórias do Instituto Oswaldo Cruz, 104, 383-388. http://dx.doi.org/10.1590/S0074-02762009000200037

[30] Dumetre, A., Le Bras, C., Baffet, M., Meneceur, P., Dubey, J.P., Derouin, F., Duguet, J.P., Joyeux, M. and Moulin, L. (2008) Effects of Ozone and Ultraviolet Radiation Treatments on the Infectivity of Toxoplasma gondii Oocysts. Veterinary Parasitology, 153, 209-213. http://dx.doi.org/10.1016/j.vetpar.2008.02.004

[31] Garcia, L.C. (2007) Toxoplasma gondii. In: Garcia, L.C., Ed., Diagnosis Medical Parasitology, ASM Press, Washington DC, 562-563.

[32] Jones, J.L., Dargelas, V., Roberts, J., Press, C., Remington, J.S. and Montoya, J.G. (2009) Risk Factors for Toxoplasma gondii Infection in the United States. Clinical Infectious Diseases, 49, 878-884. http://dx.doi.org/10.1086/605433

[33] Dos Santos, T.R., Nunes, C.M., Luvizotto, M.C., de Moura, A.B., Lopes, W.D., da Costa, A.J. and Bresciani, K.D. (2010) Detection of Toxoplasma gondii Oocysts in Environmental Samples from Public Schools. Veterinary Parasitology, 171, 53-57. http://dx.doi.org/10.1016/j.vetpar.2010.02.045

[34] Almeida, M.J., Oliveira, L.H.H., Freire, R.L. and Navarro, R.T. (2011) Aspectos sociopolíticos da epidemiologia de toxoplasmose em Santa Isabel do Ivaí (PR). Ciência \& Saúde Coletiva, 16, 1363-1373. http://dx.doi.org/10.1590/S1413-81232011000700071 


\section{استيبان عن مدى معرفنك بمرض القطط ( التوكسوبلازموسيس )}

البيانات الشخصية :

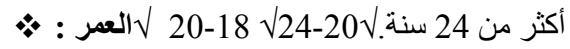

$*$ الكلية :

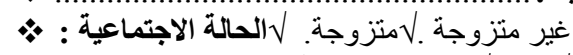

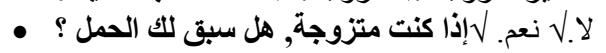

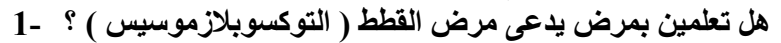

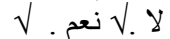

• إذا كاتت إجابتك نعم , هل تعلمين بخطورة هذا المرض أوالعوامل المؤدية إلى الإصابة به ؟ ل

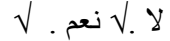

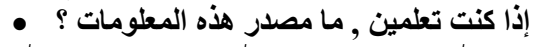

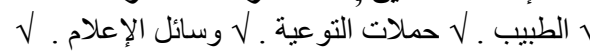

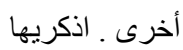

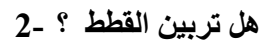

ل

- إذا كانت الإجابة بنعم , فما معدل تنظيف مكانها ل

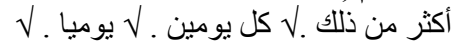

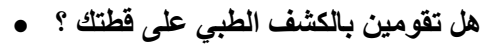

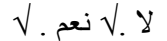

3- هل تغسلين يديك قيل تناول الطعام ؟

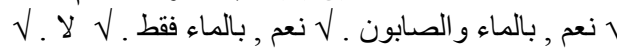
طرق إضافية ـ اذكريها . - مريه

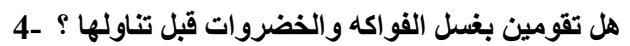

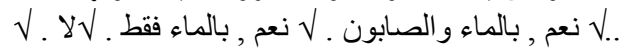
طرق إضافية ـ اذكريها

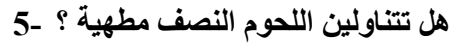

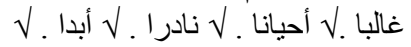

6- ما مصدر مياه شربك ؟

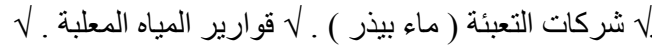
أخرى . اذكريها إذا كاتت الإجابة مياه شركات التعبئة , فما معدل تنظيف الخزان ؟

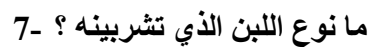

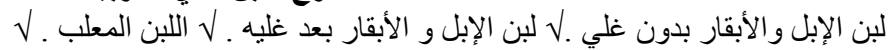

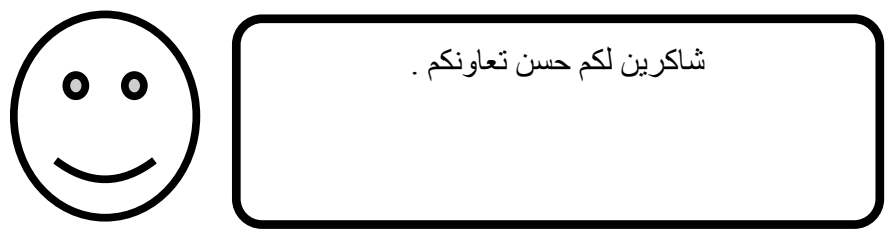

